\title{
Movement patterns of juvenile and adult noble crayfish (Astacus astacus) in a small stream, determined by radiotelemetry
}

\author{
Tomáš Daněk ${ }^{1, *}$, Jiří Musil ${ }^{1}$, Petr Vlašánek ${ }^{1}$, Jitka Svobodová ${ }^{1}$, Tereza Barteková ${ }^{1}$, David Štrunc ${ }^{1}$, \\ Miroslav Barankiewicz ${ }^{1}$, Eduard Bouše ${ }^{1}$, Eva Svobodová ${ }^{1}$, Stein I. Johnsen ${ }^{2}$ and Oddgeir Andersen ${ }^{2}$ \\ 1 T.G. Masaryk Water Research Institute, p.r.i.; Podbabská 2582/30, 16000 Prague, Czech Republic \\ ${ }^{2}$ Norwegian Institute of Nature Research; Fakkelgården, 2624 Lillehammer, Norway
}

Received: 22 May 2019; Accepted: 9 September 2019

\begin{abstract}
This article reports on the results of the first radiotelemetric field study comparing the movement patterns of juvenile and adult noble crayfish (Astacus astacus) over the 24-h cycle. During our study (in summer, outside the reproduction period), juveniles moved over significantly longer distances than adults; upstream movements prevailed in both groups. The longest distance covered by an individual crayfish during a three-hour interval was $110 \mathrm{~m}$ (in the upstream direction). Adults moved most frequently at dusk and least frequently during daytime. Among juveniles, the likelihood of movement did not significantly differ between the times of day; however, distances covered by juveniles were the longest at night and significantly shorter during daytime and at dusk. Juveniles and adults exhibited very similar local activity (motion within a single place) with high values at night and low values during daytime.
\end{abstract}

Keywords: ranging behaviour / diurnal cycle / activity / dispersal / conservation

\section{Introduction}

The noble crayfish (Astacus astacus L.) is an endangered native European species, protected in the Czech Republic as 'critically endangered' according to Decree No. 395/1992 Coll. and classified as 'vulnerable' according to the IUCN Red List of Threatened Species (IUCN, 2019). Although it is considered a flagship species in conservation studies (Reynolds and Souty-Grosset, 2011), it is still declining because of competition from alien crayfish species (e.g. Faxonius limosus Rafinesque, Pacifastacus leniusculus Dana, Procambarus clarkii Girard) and crayfish plague (Aphanomyces astaci Schikora) that they carry, among other reasons (Holdich et al., 2009). The effective protection of the noble crayfish depends on information about its movement patterns in natural habitats because they influence the spread dynamics of crayfish plague (Kadlecová et al., 2012), the ability of crayfish to recolonize depopulated areas (Schütze et al., 1999) and within- and between-species interactions (Sutherland, 1996).

Studies on the movement behaviour of various crayfish species (e.g. Procambarus clarkii, Astacopsis gouldi Clark, Cambarus chasmodactylus James) have described their nomadic behaviour, during which individuals utilize a given

\footnotetext{
*Corresponding author: tomas-danek@centrum.cz
}

patch in the vicinity of their shelter for a certain period of a few days, after which they move to another patch (Gherardi et al., 2002; Webb and Richardson, 2004; Loughman et al., 2013). Such behaviour has also been observed in the noble crayfish (Schütze et al., 1999). Robinson et al. (2000) described this behaviour using the term 'ephemeral home range'. Schütze et al. (1999) found that released individuals of the noble crayfish can migrate over distances of hundreds of metres and that the speed of their migration can reach up to dozens of metres per hour. It seems that stressful events trigger downstream migrations (Bohl, 1999; Schütze et al., 1999) whereas under favourable conditions upstream migrations may prevail (Kadlecová et al., 2012; Daněk et al., 2018).

The noble crayfish is generally considered a nocturnal species exhibiting greatest activity during dusk and at night (Abrahamsson, 1983). However, although diurnal activity rhythms are usually species-specific, in many cases they exhibit considerable variability within species. For example, subdominant individuals, in order to avoid intraspecific aggression, may be active in other periods of the day than dominant individuals (Blake et al., 1994).

Adults and juveniles may exhibit different behaviour also because of differences in their physiological requirements (Polis, 1984), different adaptability to extremes of environmental conditions (Sogard, 1997) or different sensitivity to predation (Paine, 1976; Stein and Magnuson, 1976; Stein, 1977; Keller and Moore, 1999). Behavioural patterns of 
juveniles and adults may also be influenced by food resources; however, as the species is famous for its high degree of omnivory (Lagrue et al., 2014, Weber and Traunspurger, 2017), it is not likely that food itself may cause substantial differences in the movement patterns of the two groups.

The development of advanced miniature tags has enabled the radiotelemetric tracking of juvenile crayfish individuals. Our present study is the first to compare the movement patterns of juvenile and adult noble crayfish in their natural environment by means of radiotelemetry. We assessed changes in the behaviour of free-living indigenous noble crayfish during the 24-cycle by analysing three different metrics: (i) the proportion of moving individuals, (ii) the distances covered by moving individuals and (iii) local activity of individuals (based on short-term fluctuations in radiotelemetric signal strength detected within a single position of the individual). In addition, we examined temporary changes in behaviour caused by capture and tagging.

\section{Materials and methods}

\subsection{Study site}

This study was carried out in the conditions of a small stream (currently the most typical habitat of the species in the Czech Republic). We selected as our locality the Pšovka brook near the village of Konrádov in the Czech Republic $(50.4773994 \mathrm{~N}, 14.6067517 \mathrm{E})$. It is usually less than one metre wide, shallow, almost without pools and with runs c. 5-15 cm deep. The presence of fish was not detected at the locality during the course of the study.

\subsection{Handling of crayfish}

Seventeen individuals (10 females and 7 males) of the noble crayfish (Astacus astacus) were caught on 13 July 2016 by handsearching and tagged with radiotelemetric transmitters. The handling of $A$. astacus, which is a critically endangered species in the Czech Republic, was authorized by the Nature Conservation Agency of the Czech Republic (permit SR/0065/ $\mathrm{KK} / 2016-3$ ). Females $\leq 70 \mathrm{~mm}$ and males $\leq 63 \mathrm{~mm}$ in total length (from the tip of the rostrum to the rear end of the telson) were regarded as non-reproductive and are hereafter referred to as 'juveniles', and all crayfish $\geq 80 \mathrm{~mm}$ were considered adult (Abrahamsson, 1971). The mean total length of juveniles (j1j9) and adults $(\mathrm{a} 1-\mathrm{a} 8)$ was $59.2 \mathrm{~mm}( \pm 4.8)$ and $86.8 \mathrm{~mm}( \pm 8.1)$, respectively, and their mean weight was $6.6 \mathrm{~g}( \pm 1.7)$ and $21.4 \mathrm{~g}$ $( \pm 9.8)$, respectively.

\subsection{Radiotelemetric tagging and tracking}

The individuals were tagged using NTQ 1 radio transmitters (Lotek Engineering Inc., Ontario; $0.26 \mathrm{~g}$ in air, $10 \times 5 \times 3 \mathrm{~mm}$, warranty life 17 days) with unique identification codes and subsequently tracked using a Lotek SRX 800 receiver. The transmitters were glued to the carapaces of individual crayfish using a cyanoacrylate adhesive. The tag-toanimal weight ratio represented $4.3 \%( \pm 1.5)$ of the wet body weight of juveniles and $1.4 \%( \pm 0.4)$ of the wet body weight of adults, which is less (i.e. better) than in other radiotelemetic studies on crayfish (up to $10 \%$ in Gherardi et al., 2002; up to $13.4 \%$ in Bubb et al., 2006). After tagging, the individuals were released back into their environment at the same position where they were captured. To confirm that all tracked crayfish were alive and healthy throughout the study period, we recaptured crayfish with still operating transmitters after the termination of the telemetric study but left the affixed transmitters in place to be shed at the next moulting.

Because the capture, tagging and release of individuals can trigger non-standard behaviour (i.e. a fright response; Robinson et al., 2000), radiotelemetric monitoring was not conducted in the first five days. Only the total position shift of individuals during these first five days (distance between the release point and the first position detected by radiotracking) was recorded. The short life span of the transmitters limited the duration of the radiotracking. The crayfish were tracked by radiotelemetry between 18 July and 26 July 2016 (i.e. outside the species' reproduction period) in eight 3 -h tracking intervals per day defined based on light intensity measured in exposure values (EV): one 3-h interval at dawn (2-6 EV), four during daytime $(>6 \mathrm{EV})$, one at dusk (2-6 EV) and two at night $(<2 \mathrm{EV})$. The light intensity at the site was measured during each 3-h interval at an unshaded reference point using a Gossen Digisix light meter (GOSSEN Foto- und Lichtmesstechnik $\mathrm{GmbH})$.

Within each tracking interval, whether each individual did or did not move up, down or across the stream ('movement') was recorded with precision of $0.5 \mathrm{~m}$. In cases of crayfish that did move, the distance they moved longitudinally along the stream ('distance covered') was also measured using a $30 \mathrm{~m}$ long measuring tape.

Besides shifts in positions along the stream, radiotelemetry can also be used to detect motion realized within a single position ('local activity'), for example associated with feeding, shelter upkeep or defence against invaders. Motion of an individual may alter the orientation of the transmitter's antenna in relation to the fixed Yagi antenna of the receiver and thus generate variation in the strength of the signal received (Bubb et al., 2002; Thiem et al., 2010). The local activity of individual crayfish was measured during each tracking interval within a 1-min time period (Thiem et al., 2010; Daněk et al., 2018) by recording the number of variations in signal strength as an index of local activity. Individuals exhibiting variations in signal strength exceeding the threshold value of $5 \%$ (the telemetric receiver used shows exact signal strength) were considered active in terms of local activity. The numbers of signal strength variations were classified into three levels of local activity according to Robinson et al. (2000): 0 (no variation), 1 (one to two variations) and 2 (more than two variations). During the radiotracking, we took maximum care not to disturb the crayfish. We did not detect any sudden behavioural changes of animals connected to the tracking itself.

The overall ranging behaviour during the radiotelemetric tracking was expressed as 'cumulative distance travelled', calculated for each individual as the sum of all its movements, and 'net distance travelled', calculated as the distance between the point of release and the final position of the individual detected by telemetry. To assess the extent of the fright response of tagged individuals, their ranging behaviour during the first five days after tagging was compared with that during 
the subsequent telemetric study. Values of 'range per day' (similarly as in Bubb et al., 2006), calculated by dividing the linear range by the corresponding number of days, were compared.

Water temperature $\left({ }^{\circ} \mathrm{C}\right)$ was recorded continuously using a HOBO Pendant Temperature/Light $8 \mathrm{~K}$ Data Logger (Onset Computer Corporation). Water levels were measured with a water level pole $(\mathrm{cm})$.

\subsection{Statistics}

Generalized linear mixed models (GLMM) were employed to analyse how the time of day and crayfish sex influenced (i) movement (binomial distribution, logit link), (ii) distance covered (gamma distribution, log link), and (iii) local activity (binomial distribution, logit link). For the purposes of statistical analyses, local activity levels 1 and 2 were joined together. Because multiple data points for the same crayfish were obtained, the identity of individuals was included as a random factor. The 'Ime4' package in $\mathrm{R}$ v. 3.0.3 (R Development Core Team 2008) was used. To assess model significance, the models were compared against matching null models using likelihood ratio tests. T-testing was used to compare the ranges covered by crayfish in the first five days after their release and during the subsequent telemetric study. Data are presented with standard errors of the mean (SE).

\section{Results}

\subsection{Ranging behaviour of Astacus astacus after capture and tagging}

During the first five days after capture and tagging, the range per day of individual crayfish on average reached $14.9 \mathrm{~m}$, which is significantly greater than during the subsequent telemetric study $\left(4.6 \mathrm{~m} ; t_{32}=2.112, p=0.042\right)$. The ranges covered by both juvenile and adult crayfish were highly variable, causing the differences between juveniles and adults in the distances and directions of migration to be nonsignificant. Six individuals shifted their positions by more than $100 \mathrm{~m}$, the largest recorded shift being $332 \mathrm{~m}$ (j2).

\subsection{Spatial behaviour and local activity throughout the telemetry study}

During the subsequent tracking, a total of 860 valid positions of crayfish were acquired. The directions in which the individuals moved are presented in Figure 1. In both juveniles and adults, upstream movement prevailed, but juveniles migrated over much greater distances (up to $200 \mathrm{~m}$ ) than adults, all of which, except one (a5), stayed within a range of $\pm 15 \mathrm{~m}$ from the first position ascertained during the telemetry study. Moreover, adults usually stayed at a single place for extensive periods.

The cumulative distance travelled throughout the telemetry study by juveniles and adults was $50.7 \mathrm{~m}( \pm 22.8)$ and $15.8 \mathrm{~m}$ $( \pm 5.6)$, respectively, and the net distance travelled was $44.4 \mathrm{~m}$ $( \pm 20.6)$ and $5.8 \mathrm{~m}( \pm 2.1)$, respectively. The average distance covered by moving juveniles within 3-h intervals was $13.4 \mathrm{~m}$ $( \pm 3.4)$ whereas for adults this distance was $3.2 \mathrm{~m}( \pm 0.4)$.
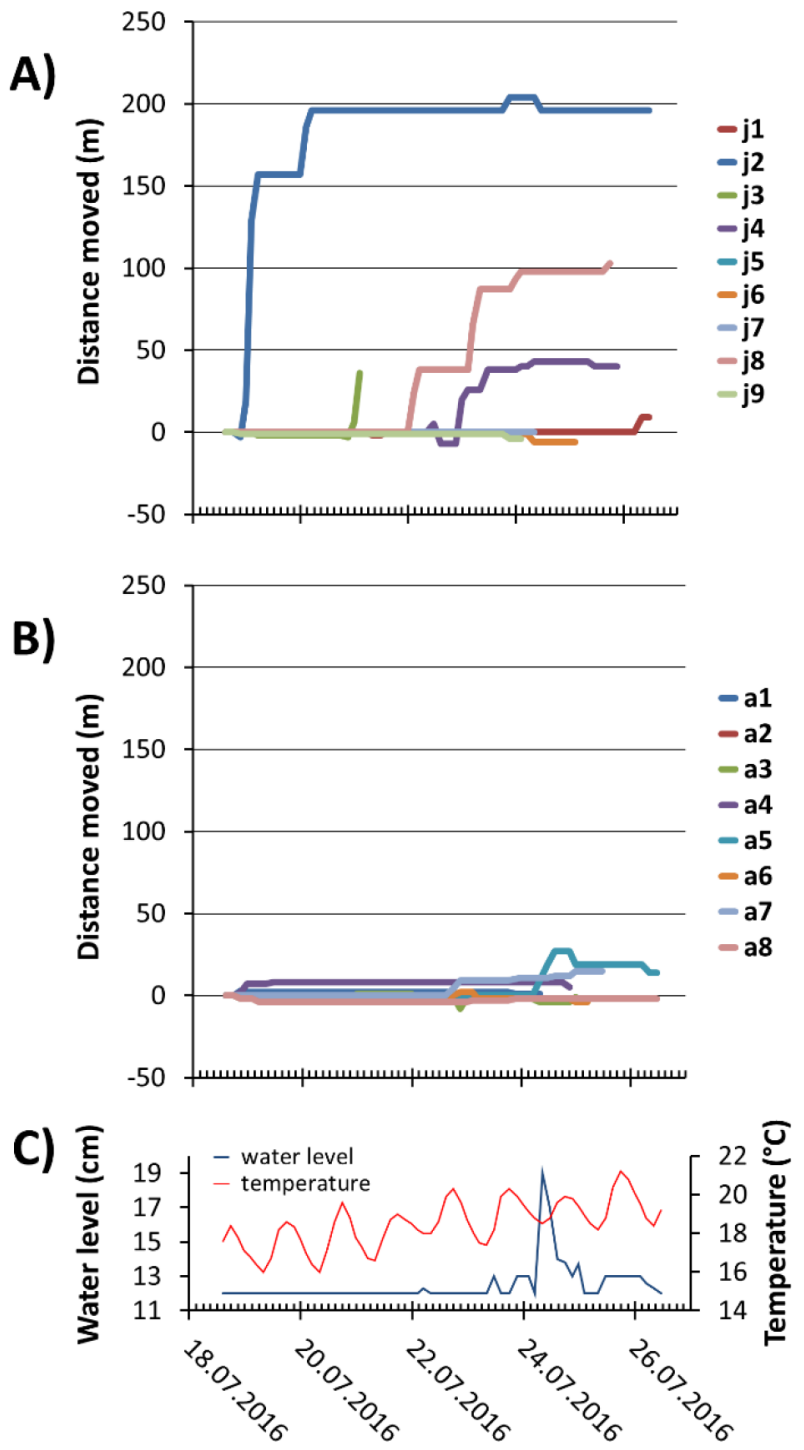

Fig. 1. Directions of movement of individual juvenile (A) and adult (B) Astacus astacus in relation with water level and temperature variations (C) during the telemetric study. Positive values of distances refer to locations upstream and negative values to locations downstream from the initial location detected by radiotelemetry.

Juveniles moved over significantly longer distances than adults $\left(t_{4,69}=-2.721, p=0.007\right)$.

The longest distance covered during a 3-h interval (juvenile female weighing $8.6 \mathrm{~g}$ ) was $110 \mathrm{~m}$ in the upstream direction. This position shift was recorded at night in the interval starting at 23:45. When taking into account the position shift during the first five days after capture and tagging, this individual covered a total distance of $489 \mathrm{~m}$ in the upstream direction in 5.5 days. The overall likelihood of movement (movement) was slightly lower for juveniles $(7.8 \% \pm 1.3)$ compared to adults $(9.9 \% \pm 1.5)$, but this difference was non-significant $\left(z_{3,828}=0.866, p=0.386\right)$. The overall local activity for juvenile and adult $A$. astacus was $17.7 \%(12.5 \%$ and $5.2 \%$ for local activity levels 1 and 2 , respectively) and $20.4 \%(15.4 \% ; 5.0 \%)$, respectively. There 
were no significant differences between the two groups in overall local activity $\left(z_{3,845}=1.028, p=0.304\right)$. Over the course of our study, there were no differences between the sexes in movement, distance covered and local activity.

\subsection{Behaviour at different times of day}

Juveniles and adults differed in the distribution of their movement during the 24-h cycle (Fig. 2A). Whereas the movement of juveniles did not significantly differ between the times of day $\left(\chi^{2}{ }_{3}=3.153 ; p=0.369\right)$, in adults the time of day had a significant effect $\left(\chi^{2}{ }_{3}=16.683 ; p<0.001\right)$. The movement for adults was lowest during daytime and highest at dusk. Moreover, adults were significantly more likely to move at dusk than juveniles $\left(z_{3,107}=1.991, p=0.047\right)$.

Differences in distance covered by moving juvenile and adult crayfish during different times of day (dawn, daytime, dusk and night) are presented in Figure 2B. Whereas in adults distance covered did not significantly differ between the times of day $\left(\chi_{3}^{2}=0.565 ; p=0.904\right)$, in juveniles it changed considerably $\left(\chi^{2}{ }_{3}=15.150 ; p=0.002\right)$. The longest distances were covered by juveniles at night. Conversely, during daytime and at dusk the distances covered were shorter than at night. The most pronounced difference in distance covered for juveniles and adults was observed at night (juveniles: $22.58 \mathrm{~m} \pm 8.57$; adults: $2.93 \mathrm{~m} \pm 0.58$ ), and this difference was highly significant $\left(t_{4,22}=-3.638, p<0.001\right)$.

Local activity varied between different phases of the diel cycle significantly among juveniles $\left(\chi_{3}^{2}=31.945 ; p<0.001\right)$ as well as among adults $\left(\chi_{3}^{2}=15.095 ; p=0.002\right)$. Changes in local activity were analogous in juveniles and adults, and there were no significant differences between juveniles and adults during particular times of day (Fig. 2C). Neither in juveniles nor in adults did we detect high local activity (local activity level 2) during daytime whereas at dusk and at night this level of activity was comparatively frequent. Altogether, juveniles were significantly most active at night and least active during daytime. Adults were most active at night and at dusk, and least active during daytime.

\section{Discussion}

Movement patterns of crayfish, especially of invasive species, have been studied extensively (e.g. Gherardi et al., 2002; Bubb et al., 2002). However, in the case of the noble crayfish, an important native European species, movement patterns in the natural environment are relatively poorly known. Our study is the first to compare the natural movement patterns of juvenile and adult noble crayfish by methods of radiotelemetry.

Analysis of changes in range per day found the ranging behaviour of crayfish to be significantly elevated in the first five days after their release, so postponing the beginning of the radiotracking of natural behaviour was appropriate (Barbaresi et al., 2004). During our telemetric tracking, crayfish moved mainly in the upstream direction in both juveniles and adults. However, the tendency to move in this direction was more pronounced in juveniles. After the crayfish migrated, they usually did not return to a previously occupied shelter, so homing behaviour obviously did not play any significant role at
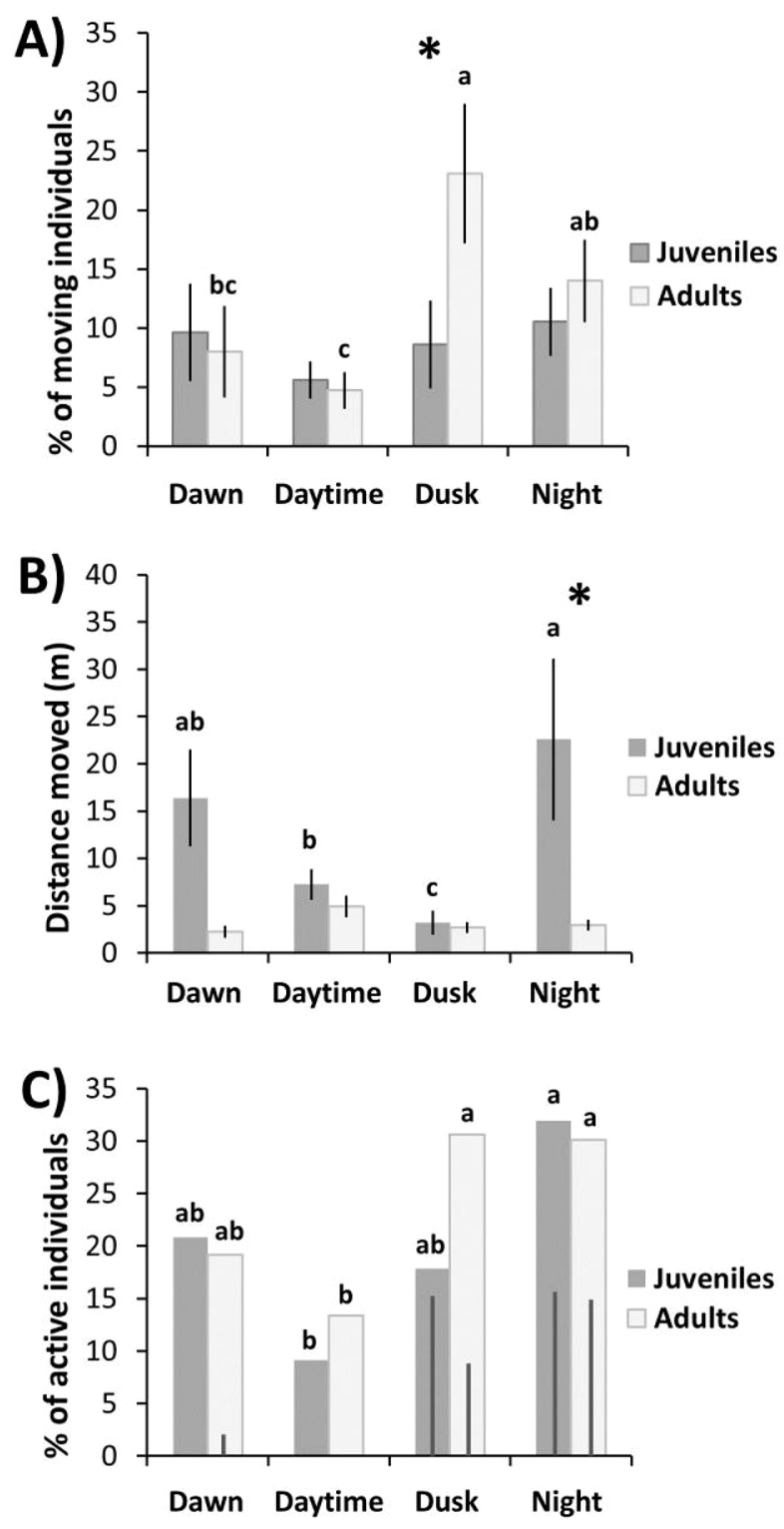

Fig. 2. Movement likelihood (A), distance covered by moving individuals (B) and local activity (C) of juvenile and adult Astacus astacus within three-hour tracking intervals at different times of day. Asterisks indicates significant differences in behavioural metrics between juvenile and adult crayfish during particular times of day. Different letters indicate significant differences between dawn, daytime, dusk and night intervals among juvenile and adult crayfish, respectively. Levels of local activity were determined during 1-min time periods by counting the number of variations in signal strength as an index of activity according to Robinson et al. (2000): 0 (no variation), 1 (one to two variations) and 2 (more than two variations). The extent of level 2 (high) local activity is indicated in particular columns as a black bar.

the locality. The prevailing upstream movement is in agreement with observations made by Hudina et al. (2008), Kadlecová et al. (2012) and Daněk et al. (2018), and it probably helps crayfish to counteract occasional passive downstream movements during extreme flow (Momot, 1966). Migrations of juvenile individuals over longer distances may 
be associated with their smaller drag when moving against the flow (Hudina et al., 2008), but they may also be connected with their preference of shallower parts of the watercourse or its tributaries higher upstream, compared to the suggested preference of adults for deeper sections (Skurdal et al., 1988; Harrison et al., 2006).

The distances covered by moving individuals and associated speeds of relocation were comparable with values reported by other authors. The furthest position shift within a 3 -h interval was over $110 \mathrm{~m}$, which is in agreement with the maximum speeds of $40-50 \mathrm{~m} \cdot \mathrm{h}^{-1}$ mentioned by Schütze et al. (1999). Juvenile crayfish in our study, however, generally moved over longer distances than adults. This may to a certain extent be explained by agonistic behaviour of adults. Weaker juveniles are likely to lose fights over shelters, so they may be forced to relocate in order to find new ones (Harrison et al., 2006).

At different times of day, the behavioural metric movement changed in adult crayfish whereas juvenile individuals showed no significant changes in this regard. Adults were most active at dusk, in agreement with previous studies (e.g. Abrahamsson, 1983; Musil et al., 2010). For juveniles, a more uniform distribution of movement might constitute a certain compromise between avoiding predation pressure during daytime and encounters with agonistic adults at dusk (Blake et al., 1994; Goessmann et al., 2000).

As regards distance covered, the situation is different. In juveniles the distances covered changed significantly between the times of day whereas in adults such changes were nonsignificant. It should be kept in mind that adults generally moved over much shorter distances (i.e. close to their shelters). Short-distance movements by adults are therefore less risky than long-distance movements by juveniles, which may be forced to concentrate their movements to more favourable times of day, when there is neither a higher risk of predation (during daytime) nor an increased likelihood of encountering an agonistic adult (at dusk, when adults move most frequently). Accordingly, juveniles in our study covered significantly the longest distances during night-time intervals whereas their movements were significantly shorter during daytime and at dusk.

Another metric of animal behaviour examined here is local activity, which includes motion within a single place. Because this can be realized within a shelter, it is less influenced by predation or agonistic behaviour. We were therefore not surprised by the highly similar patterns of local activity in juveniles and adults (without any significant differences), with high values during dusk and at night. This only confirms that A. astacus is primarily a nocturnal and crepuscular species (Abrahamsson, 1983; Skurdal and Taugbøl, 2002).

To conclude, our study expands the knowledge of the ranging behaviour of $A$. astacus in its natural environment and indicates that movement patterns of juvenile and adult noble crayfish differ substantially. We suggest that the differences we observed were, to a certain degree, caused by intraspecific agonistic behaviour. Our results also suggest that during the summer season, juveniles are better dispersers than adults. Future, more extensive telemetric studies are necessary to examine the ranging behaviour of the species in different seasons (including e.g. the mating or hatching periods), in other types of habitat (e.g. fast-running streams with a rocky bottom or lentic ecosystems) and at localities differing in predation pressure.

Acknowledgements. We thank Shiferaw Demeke, Zuzana Hořická and Vojtěch Mrázek for their field assistance and two anonymous referees for their valuable comments on an earlier draft of the manuscript. This study was supported by the EEA grant EHP-CZ02-OV-1-019-01-2014 ('Monitoring of NATURA 2000 sites as a tool for effective management and conservation of autochthonous crayfish'), funded by Iceland, Liechtenstein and Norway, along with the Czech Ministry of the Environment fund for long-term conceptual institutional development.

\section{References}

Abrahamsson SAA. 1971. Density, growth and reproduction in populations of Astacus astacus and Pacifastacus leniusculus in an isolated pond. Oikos 22: 373-380.

Abrahamsson S. 1983. Trappability, locomotion, and diel pattern of activity of the crayfish Astacus astacus and Pacifastacus leniusculus Dana. Freshw Crayfish 5: 239-253.

Barbaresi S, Santini G, Tricarico E, Gherardi F. 2004. Ranging behaviour of the invasive crayfish, Procambarus clarkii (Girard). $J$ Nat Hist 38: 2821-2832.

Blake M, Nyström P, Hart P. 1994. The effect of weed cover on juvenile signal crayfish (Pacifasticus leniusculus Dana) exposed to adult crayfish and non-predatory fish. Ann Zool Fennici 31: 297306.

Bohl E. 1999. Motion of individual noble crayfish Astacus astacus in different biological situations: in-situ studies using radio telemetry. Freshw Crayfish 12: 677-687.

Bubb DH, Lucas MC, Thom TJ. 2002. Winter movements and activity of signal crayfish Pacifastacus leniusculus in an upland river, determined by radio telemetry. Hydrobiologia 483: 111-119.

Bubb DH, Thom TJ, Lucas MC. 2006. Movement, dispersal and refuge use of co-occurring introduced and native crayfish. Freshw Biol 51: 1359-1368.

Daněk T, Musil J, Vlašánek P et al. 2018. Telemetry of co-occurring noble crayfish (Astacus astacus) and stone crayfish (Austropotamobius torrentium): diel changes in movement and local activity. Fund Appl Limnol 191: 339-352.

Gherardi F, Tricarico E, Ilhéu M. 2002. Movement patterns of an invasive crayfish, Procambarus clarkii, in a temporary stream of southern Portugal. Ethol Ecol Evol 14: 183-197.

Goessmann C, Hemelrijk C, Huber R. 2000. The formation and maintenance of crayfish hierarchies: behavioral and self-structuring properties. Behav Ecol Sociobiol 48: 418-428.

Harrison ML, Hoover TM, Richardson JS. 2006. Agonistic behaviours and movement in the signal crayfish, Pacifastacus leniusculus: can dominance interactions influence crayfish sizeclass distributions in streams? Can J Zool 84: 1495-1504.

Holdich DM, Reynolds JD, Souty-Grosset C, Sibley PJ. 2009. A review of the ever increasing threat to European crayfish from nonindigenous crayfish species. Knowl Manag Aquat Ecosyst 394-395: 11.

Hudina S, Maguire I, Klobučar GIV. 2008. Spatial dynamics of the noble crayfish (Astacus astacus, L.) in the Paklenica National Park. Knowl Manag Aquat Ecosyst 388: 01.

IUCN. 2019. The IUCN Red List of Threatened Species. Version 2019-2. https://www.iucnredlist.org

Kadlecová K, Bílý M, Maciak M. 2012. Movement patterns of the co-occurring species Astacus astacus (noble crayfish) and 
Austropotamobius torrentium (stone crayfish). Fund Appl Limnol 180: 351-360.

Keller TA, Moore PA. 1999. Effects of ontogeny and odors on behavior: the influence of crayfish size and fish odors on crayfish movement. Mar Freshw Behav Phys 33: 35-50.

Lagrue C, Podgorniak T, Lecerf A, Bollache L. 2014. An invasive species may be better than none: invasive signal and native noble crayfish have similar community effects. Freshw Biol 59: 19821995.

Loughman ZJ, Skalican KT, Taylor ND. 2013. Habitat selection and movement of Cambarus chasmodactylus (Decapoda: Cambaridae) assessed via radio telemetry. Freshw Sci 32: 1288-1297.

Momot MT. 1966. Upstream movement of crayfish in an intermittent Oklahoma stream. Am Midl Nat 75: 150-159.

Musil M, Buřič M, Policar T, Kouba A, Kozák P. 2010. Comparison of diurnal and nocturnal activity between noble crayfish (Astacus astacus) and spinycheek crayfish (Orconectes limosus). Freshw Crayfish 17: 189-193.

Paine RT. 1976. Size-Limited Predation: an observational and experimental approach with the mytilus-pisaster interaction. Ecology 57: 858-873.

Polis GA. 1984. Age structure component of niche width and intraspecific resource partitioning: can age groups function as ecological species? Am Nat 123: 541-564.

Reynolds J, Souty-Grosset C. 2011. Management of freshwater biodiversity: crayfish as bioindicators. Cambridge: Cambridge University Press, $374 \mathrm{p}$.

Robinson CA, Thom TJ, Lucas MC. 2000. Ranging behaviour of a large freshwater invertebrate, the white-clawed crayfish Austropotamobius pallipes. Freshw Biol 44: 509-521.
Schütze S, Stein H, Born O. 1999. Radio telemetry observations on migration and activity patterns of restocked noble crayfish Astacus astacus (L.) in the small river Sempt, north-east of Munich, Germany. Freshw Crayfish 12: 688-695.

Skurdal J, Fjeld E, Hessen DO, Taugbøl T, Dehli E. 1988. Depth distribution, habitat segregation and feeding of the crayfish Astacus astacus in Lake Steinsfjorden. Nord J Freshw Res 64: 113-119.

Skurdal J, Taugbøl T. 2002. Astacus. In: Holdich DM (ed.), Biology of Freshwater Crayfish. Oxford: Blackwell Science, pp. 467-510.

Sogard SM. 1997. Size-selective mortality in the juvenile stage of teleost fishes: a review. Bull Mar Sci 60: 1129-1157.

Stein RA. 1977. Selective predation, optimal foraging, and the predator-prey interaction between fish and crayfish. Ecology 58: 1237-1253.

Stein RA, Magnuson JJ. 1976. Behavioral response of crayfish to a fish predator. Ecology 57: 751-761.

Sutherland WJ. 1996. From individual behaviour to population ecology. Oxford: Oxford University Press, 213 p.

Thiem JD, Ebner BC, Clear RC. 2010. Validating variation in radiosignal strength as an index of aquatic fauna activity. Aust J Zool 58: $50-55$.

Webb M, Richardson A. 2004. A radio telemetry study of movement in the giant Tasmanian freshwater crayfish, Astacopsis gouldi. Freshw Crayfish 14: 197-204.

Weber S, Traunspurger W. 2017. Invasive red swamp crayfish (Procambarus clarkii) and native noble crayfish (Astacus astacus) similarly reduce oligochaetes, epipelic algae, and meiofauna biomass: a microcosm study. Freshw Sci 36: 103-112.

Cite this article as: Daněk T, Musil J, Vlašánek P, Svobodová J, Barteková T, Štrunc D, Barankiewicz M, Bouše E, Svobodová E, Johnsen SI, Andersen O. 2019. Movement patterns of juvenile and adult noble crayfish (Astacus astacus) in a small stream, determined by radiotelemetry. Ann. Limnol. - Int. J. Lim. 55: 19 